\title{
An over-the-scope clip placed for large colonic perforation can be complicated by delayed bleeding despite its known hemostatic mechanical effect
}

The efficacy and safety of the over-thescope clip (OTSC) to manage acute gastrointestinal defects have been demonstrated for several years [1]. Data have shown a technical success rate of almost $100 \%$ [2], with very good safety [3]. The most common complication after the use of an OTSC for acute gastrointestinal defects is peritonitis, which occurs when leaks remain [4]. We present a case of delayed bleeding after the closure of an iatrogenic colonic perforation with an OTSC ( $\triangleright$ Video 1 ).

A 48-year-old woman underwent a colonoscopy to rule out a colorectal tumor in the context of paraneoplastic polymyositis with severe malnutrition and ongoing corticosteroid therapy over several days. The colonoscopy was complicated by a sigmoid perforation caused by the scope $(>1 \mathrm{~cm})$. This iatrogenic perforation was managed as per procedure by placement of an OTSC, with technical success. No surgery was necessary in the aftermath. However, 6 days after the successful closure, the patient developed hematochezia and a fall in her hemoglobin was noted. At the time, she was receiving ongoing anticoagulation for a mechanical mitral valve. A second endoscopy confirmed that there was bleeding at the site of the OTSC ( $\mathbf{F i g . 1}$ a). In fact, an enlarged pulsating vessel with active nonpulsating bleeding could be seen in the middle of the clip teeth ( $\boldsymbol{\nabla}$ Fig. $\mathbf{1}$ b, c). Hemostasis was achieved with hot biopsy forceps coagulation ( $\triangleright$ Fig. 1 d).

This case highlights an unusual outcome of an OTSC that has not been well described in safety studies [4]. Furthermore, it is important to be aware of this surprising cause of bleeding, even though OTSCs are well known for their use in controlling bleeding.

In conclusion, bleeding can be a complication of an OTSC and it can present in a delayed manner. Despite the hemostatic

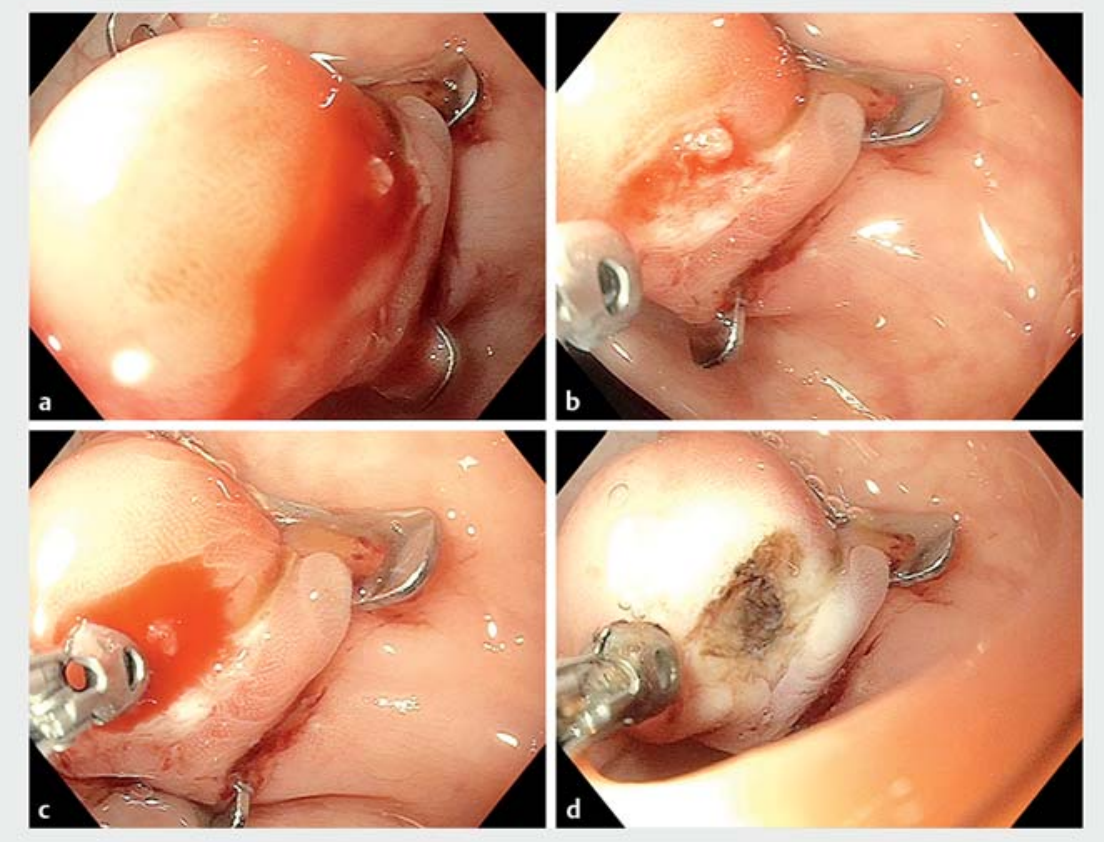

- Fig. 1 Endoscopic images of delayed bleeding complicating the placement of an over-thescope clip (OTSC) for colonic perforation showing: a bleeding from the center of the mucosa that had been trapped into the OTSC; $\mathbf{b}$ a vessel drawn into the OTSC teeth; $\mathbf{c}$ active bleeding after contact with the forceps; $\mathbf{d}$ the appearance after hot biopsy forceps coagulation.

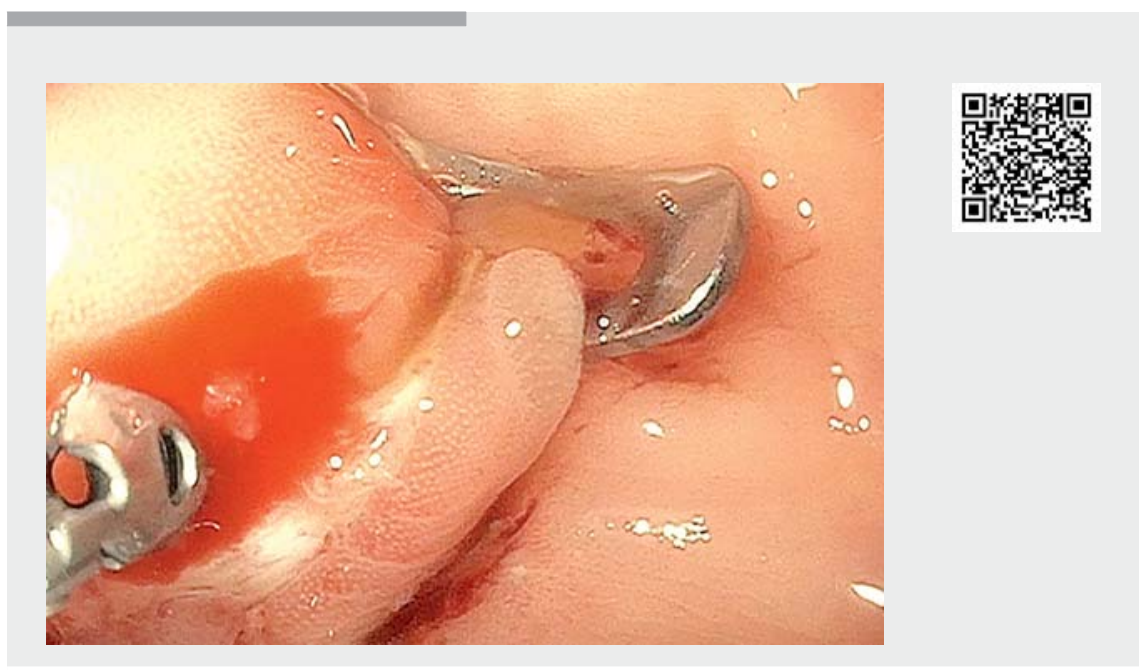

$\checkmark$ Video 1 An over-the-scope clip (OTSC) placed for a large colonic perforation was complicated by delayed bleeding despite its known hemostatic mechanical effect. 
features of OTSCs, it is important to do a second-look endoscopy to re-examine the OTSC site in patients who present with delayed bleeding.

Endoscopy_UCTN_Code_CPL_1AJ_2AZ

\section{Competing interests}

None

The authors

Armelle Schoch ${ }^{1}$, Gaspard Bertrand ${ }^{1}$, Jérôme Rivory ${ }^{1}$, Myrtille Fouche ${ }^{2}$, Hugo Tête ${ }^{2}$, Julie Perinel $^{3}$, Mathieu Pioche ${ }^{1}$

1 Department of Endoscopy and Gastroenterology, Pavillon L, Edouard Herriot Hospital, Lyon, France

2 Anesthesiology department, Pavillon L, Edouard Herriot Hospital, Lyon, France

3 Department of Visceral Surgery, Pavillon D, Edouard Herriot Hospital, Lyon, France
Corresponding author

\section{Mathieu Pioche, MD}

Endoscopy unit - Digestive Disease department, Pavillon L - Edouard Herriot Hospital, 69437 Lyon, France mathieu.pioche@chu-lyon.fr

\section{References}

[1] Nishiyama N, Mori H, Kobara H et al. Efficacy and safety of over-the-scope clip: including complications after endoscopic submucosal dissection. World J Gastroenterol 2013; 19: 2752-2760

[2] Goenka MK, Rai VK, Goenka U et al. Endoscopic management of gastrointestinal leaks and bleeding with the over-the-scope clip: a prospective study. Clin Endosc 2017; 50: 58-63

[3] Raithel M, Albrecht H, Scheppach W et al. Outcome, comorbidity, hospitalization and 30-day mortality after closure of acute perforations and postoperative anastomotic leaks by the over-the-scope clip (OTSC) in an unselected cohort of patients. Surg Endosc 2017; 31: 2411-2425
[4] Manta R, Mangiafico S, Zullo A et al. Firstline endoscopic treatment with over-thescope clips in patients with either upper or lower gastrointestinal bleeding: a multicenter study. Endosc Int Open 2018; 6: E1317E1321

Bibliography

DOI https://doi.org/10.1055/a-1022-4187

Published online: 25.10.2019

Endoscopy 2020; 52: E118-E119

(c) Georg Thieme Verlag KG

Stuttgart · New York

ISSN 0013-726X

\section{ENDOSCOPY E-VIDEOS}

https:|/eref.thieme.de/e-videos

Endoscopy E-Videos is a free access online section, reporting 靣: on interesting cases and new techniques in gastroenterological endoscopy. All papers include a high quality video and all contributions are freely accessible online.

This section has its own submission website at https://mc.manuscriptcentral.com/e-videos 